\title{
PERSPECTIVE OPEN \\ Interstitial lung disease: raising the index of suspicion in primary care
}

\author{
Joseph D Zibrak ${ }^{1}$ and David Price ${ }^{2}$
}

\begin{abstract}
Interstitial lung disease (ILD) describes a group of diseases that cause progressive scarring of the lung tissue through inflammation and fibrosis. The most common form of ILD is idiopathic pulmonary fibrosis, which has a poor prognosis. ILD is rare and mainly a disease of the middle-aged and elderly. The symptoms of ILD—chronic dyspnoea and cough-are easily confused with the symptoms of more common diseases, particularly chronic obstructive pulmonary disease and heart failure. ILD is infrequently seen in primary care and a precise diagnosis of these disorders can be challenging for physicians who rarely encounter them. Confirming a diagnosis of ILD requires specialist expertise and review of a high-resolution computed tomography scan (HRCT). Primary care physicians (PCPs) play a key role in facilitating the diagnosis of ILD by referring patients with concerning symptoms to a pulmonologist and, in some cases, by ordering HRCTs. In our article, we highlight the importance of prompt diagnosis of ILD and describe the circumstances in which a PCP's suspicion for ILD should be raised in a patient presenting with chronic dyspnoea on exertion, once more common causes of dyspnoea have been investigated and excluded.
\end{abstract}

npj Primary Care Respiratory Medicine (2014) 24, 14054; doi:10.1038/npjpcrm.2014.54; published online 11 September 2014

\section{INTRODUCTION}

Interstitial lung disease (ILD) is an umbrella term, synonymous with diffuse parenchymal lung disease, for a large group of lung diseases affecting the tissue and space around the air sacs of the lungs, which cause progressive scarring of lung tissue through inflammation and fibrosis. ${ }^{1}$ ILD is uncommon compared to other pulmonary problems seen in general practice. The prevalence of ILD has been estimated as $81 / 100,000$ in males and $67 / 100,000$ in females. ${ }^{2}$

Primary care physicians (PCPs) often misdiagnose ILD as chronic obstructive pulmonary disease (COPD), bronchitis, emphysema, asthma, heart disease or other common diseases with similar symptoms. ${ }^{3}$ In a US survey of 1,583 patients, $54.6 \%$ reported a delay of $\geqslant 1$ year between the onset of breathing problems and receiving a diagnosis of pulmonary fibrosis. ${ }^{3}$

A diagnosis of ILD should be confirmed by a pulmonologist working with a radiologist experienced in the differential diagnosis of ILD, but PCPs have a crucial role to play in recognising the need for further evaluation. This paper describes the circumstances in which a PCP's suspicion for ILD should be raised in a patient with chronic dyspnoea and the importance of referring patients who may have ILD promptly to a pulmonologist to confirm the diagnosis.

\section{WHAT IS ILD?}

The American Thoracic Society and European Respiratory Society define ILD as a heterogeneous group of non-neoplastic disorders resulting from damage to the lung parenchyma by inflammation and fibrosis that diminish the lung's capacity for alveolar gas diffusion. ${ }^{1}$ The latest classification of ILDs is shown in Figure 1.,4 Most ILDs are 'restrictive' pulmonary disorders, i.e., the lungs have a reduced ability to expand on inhalation. This is in contrast to 'obstructive' pulmonary disorders such as asthma, COPD and emphysema, in which the airways of the lungs become narrowed or blocked so the patient cannot exhale completely. Some forms of ILD are associated with environmental or occupational exposures (e.g., asbestosis or silicosis), the use of certain drugs ${ }^{5}$ or with connective tissue disorders. ${ }^{2,6,7}$ Others, including the idiopathic interstitial pneumonias, have no known cause. ${ }^{1}$ Some cases of ILD do not meet the specific definitions for any form of ILD and are considered 'unclassifiable'. This may be the case when there are non-specific or conflicting clinical, radiological or histopathological findings, or when patients are unable or unwilling to undergo diagnostic procedures. ${ }^{8}$

Idiopathic pulmonary fibrosis (IPF) is the most common idiopathic interstitial pneumonia. ${ }^{1}$ IPF also has the worst prognosis; the 5 -year survival rate $(20-40 \%)^{9}$ is lower than many common cancers. ${ }^{10}$ While most cases of IPF are sporadic, familial forms of the disease may account for $\sim 5-20 \%$ of cases. ${ }^{11,12}$ The prevalence of IPF in the US has been estimated as 14.0-27.9 cases $/ 100,000$ using narrow case definitions and as 42.7-63 cases/100,000 using broad case definitions. ${ }^{13}$ In Europe, the estimated prevalence of IPF was $1.25-23.4$ cases/100,000. ${ }^{13}$ The incidence of IPF increased with age and was higher in men than in women (10.7 vs. 7.4 per 100,000 patient-years in the US). ${ }^{13}$

\section{RECOGNISING ILD}

As highlighted in the international guidelines for the diagnosis of ILD, a diagnosis of ILD should be made by review of clinical, pulmonary, radiological and possibly histopathological features. ${ }^{4}$ However, PCPs have a key role to play in identifying patients who may have ILD and referring them to a pulmonologist or an ILD clinic with a multidisciplinary team. PCPs can also help detect non-idiopathic forms of ILD by reviewing relevant occupational, environmental and drug exposures, as well as by assessing the presence of extrapulmonary symptoms suggestive of connective tissue disease.

\footnotetext{
${ }^{1}$ Beth Israel Deaconess Medical Centre, Harvard Medical School, Boston, MA, USA and ${ }^{2}$ Division of Applied Health Sciences, University of Aberdeen, Aberdeen, UK. Correspondence: JD Zibrak (jzibrak@caregroup.harvard.edu)

Received 1 October 2013; revised 2 July 2014; accepted 8 July 2014 


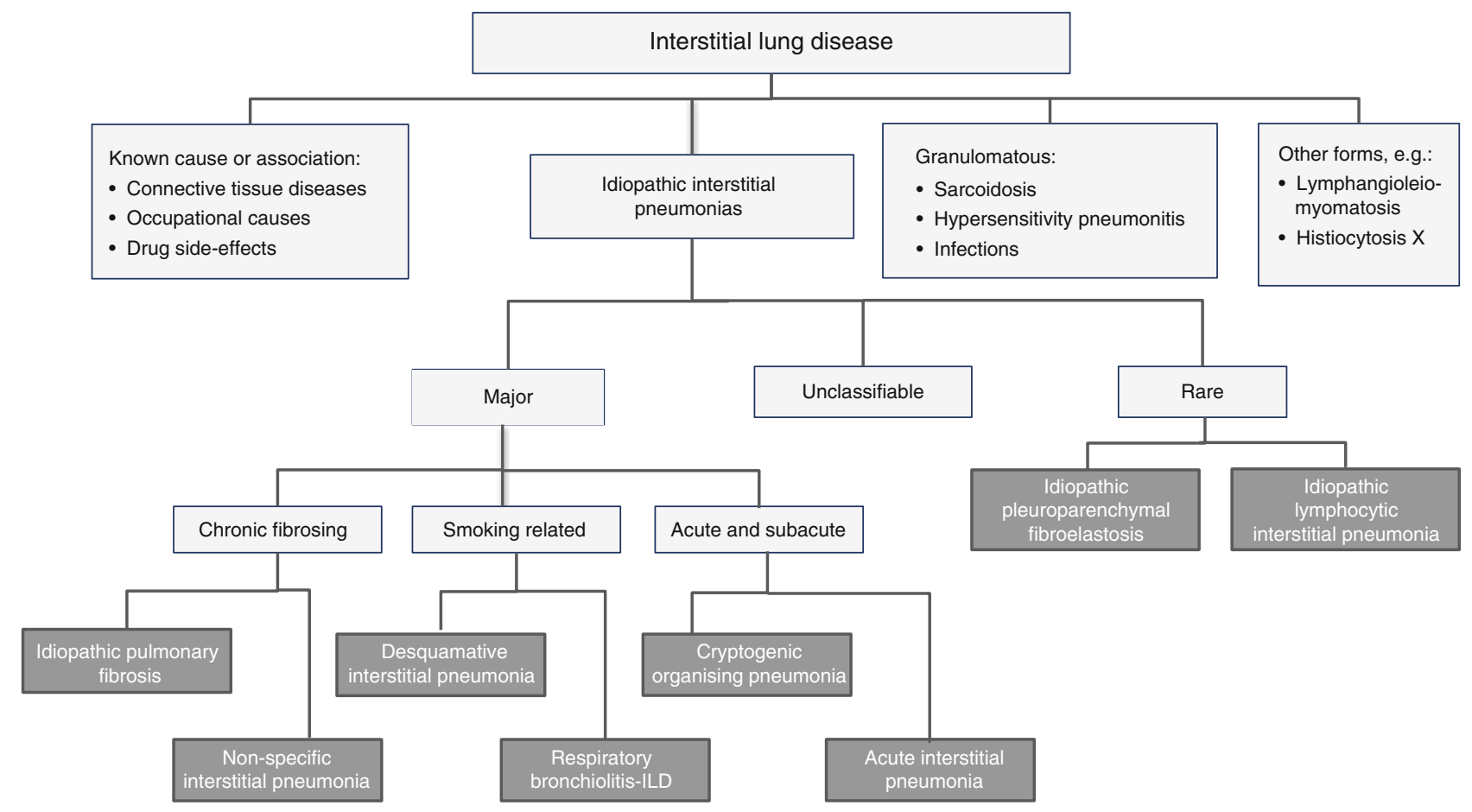

Figure 1. Classification of ILDs. ${ }^{4}$

One of the challenges for PCPs in determining whether a patient may have ILD is the lack of specificity of its symptoms. Breathlessness and cough are seen in many diseases that commonly occur in middle-aged and elderly patients, most notably COPD and heart failure. Once non-respiratory causes of breathlessness have been excluded, PCPs should consider the possibility of ILD in all middle-aged or elderly patients who present with unexplained chronic dyspnoea on exertion, particularly those who are more breathless than would be expected based on their lung function and other contributory factors such as obesity, or who have a cough of more than several months' duration. The suspicion of ILD should be raised in patients with a presumptive obstructive lung disease or congestive heart failure who fail to benefit from regular therapy, and in patients with a non-specific chest X-ray.

A diagnosis of asthma or COPD should be confirmed using the appropriate diagnostic criteria. If diagnostic criteria are not met, further assessments should be performed to ensure that the correct diagnosis is made and patients are not given inappropriate therapies. A diagnosis of COPD should be confirmed by spirometry. Obstructive lung disease is characterised by a disproportionate reduction of maximal airflow from the lung in relation to the maximal volume that can be displaced from the lung (forced vital capacity (FVC)), defined by a significantly reduced forced expiratory volume in $1 \mathrm{~s}\left(\mathrm{FEV}_{1}\right) / \mathrm{FVC}$ ratio. ${ }^{14}$ Spirometry may be normal in the early phases of ILD, and patients with both pulmonary fibrosis and emphysema often have lung volumes within normal limits. ${ }^{15}$ However, restrictive lung disease tends to be characterised by a reduction in total lung capacity and a normal or elevated $\mathrm{FEV}_{1} /$ vital capacity ratio. ${ }^{16}$ Patients with ILD tend to show a reduced FVC, which declines as the disease progresses, ${ }^{17}$ and many experience oxygen desaturation with only minimal exertion. PCPs often order chest radiographs in patients with chronic respiratory symptoms. As patients with COPD have largely normal chest radiographs, the presence of even subtle abnormalities such as increased interstitial markings or nodular opacities warrants further investigation. Patients presenting with a history of $\geqslant 6$ months' breathlessness on exertion with no evidence of obstruction should be assessed for conditions that may cause breathlessness, such as chronic heart failure, asthma, COPD, bronchiectasis, pleural effusion, abdominal splinting and anaemia. ${ }^{18}$ If these conditions are not present, patients should not only have spirometry and diffusing capacity for carbon monoxide measured, but also be referred for a highresolution computed tomography scan. High-resolution computed tomography scans are vital for the diagnosis of ILD and allow for differentiation among the types of ILD. ${ }^{19}$

PCPs should take a comprehensive medical history in all patients presenting with chronic dyspnoea, including questions about their employment history, as some forms of ILD such as asbestosis and silicosis are linked to environmental factors, ${ }^{1}$ and individuals who have worked with livestock or birds, or been subjected to high exposure to dust or fumes, may have a higher risk of IPF. ${ }^{20}$ A medical history may reveal the use of medications that may cause drug-induced ILD (DILD), such as chemotherapeutic agents (e.g., cyclophosphamide, carmustine, busulphan), antibacterial agents (e.g., sulphonamide, nitrofurantoin) or cardiovascular agents (e.g., amiodarone). ${ }^{5}$ The likelihood of developing DILD is idiosyncratic and largely unpredictable and the underlying mechanisms are not fully understood. ${ }^{5}$ PCPs should also assess for extrapulmonary symptoms, such as fatigue, joint pain and stiffness, which may suggest connective tissue disease. ${ }^{20}$

An early clinical test that can aid diagnosis of ILD is lung auscultation. Patients with many types of ILD commonly present with inspiratory 'crackles'. These crackles, which are discontinuous, short sounds similar to those heard when slowly separating Velcro, are heard even in the early stages of ILD when the patient takes slow, deep breaths. ${ }^{21}$ Unlike the crackles occasionally heard in healthy elderly subjects, which disappear after several deep breaths, these fine crackles are heard consistently at end inspiration and originate from the basal areas of the lung, progressing to the upper zones as disease becomes more severe. ${ }^{21}$ Although higher in frequency, ${ }^{21}$ crackles associated with ILD may be confused with the crackles heard in patients with heart failure. Finger clubbing, where reduced oxygenation of the blood 
causes the fingertips and fingernails to spread out and become rounder, is seen in $25-50 \%$ of patients with IPF. ${ }^{22}$

The differential features of ILD and COPD are shown in Table 1.

\section{IMPORTANCE OF PROMPT DIAGNOSIS OF ILD}

Patients with ILD who are misdiagnosed may receive inappropriate and ineffective treatment. Such treatment may be harmful physically (e.g., patients may experience adverse effects of medication without gaining any benefit) or psychologically (e.g., it is disheartening for patients to be given several treatments that do not work). There are few recommended treatments for ILD, although corticosteroids appear to be effective in the treatment of cryptogenic organising pneumonia and desquamative interstitial pneumonia. ${ }^{23}$ The latest international guidelines for the management of IPF, issued in 2011, did not recommend any specific pharmacological treatments for the chronic treatment of IPF, but long-term oxygen therapy was strongly recommended for patients with clinically significant resting hypoxaemia and a weak recommendation was made for pulmonary rehabilitation in the majority of patients. ${ }^{12}$

The anti-fibrotic agent pirfenidone has been approved for the treatment of IPF in Japan, India, China and Canada and for the treatment of mild to moderate IPF in Europe, but has not been approved in the US. An additional Phase III trial of pirfenidone has recently reported results and showed that pirfenidone reduced the decline in FVC percent predicted. ${ }^{24}$ There are several other agents in clinical development for the treatment of IPF, the most advanced of which is the tyrosine kinase inhibitor nintedanib, for which the results of two Phase III INPULSIS trials have recently been announced. ${ }^{25}$ In both the INPULSIS trials, nintedanib significantly reduced the decline in FVC over the 52-week treatment period, consistent with a slowing of disease progression. In contrast, warfarin and triple therapy with prednisone, azathioprine and $\mathrm{N}$-acetylcysteine have been shown to be harmful for patients with IPF, ${ }^{26,27}$ highlighting the importance of potential therapies being evaluated in controlled trials before they are used in clinical practice. Acetylcysteine alone appears not to be harmful, but to have no efficacy as a treatment for IPF. ${ }^{28}$

PCPs treating patients with ILD should address comorbidities such as gastroesophageal reflux disease, pulmonary hypertension $\mathrm{PH}$ ) and emphysema. The prevalence of gastroesophageal reflux disease in patients with ILD 29 and IPF ${ }^{30}$ is very high and there is some evidence that the use of gastroesophageal reflux disease treatments in patients with IPF is a predictor of longer survival time. $^{31} \mathrm{PH}$ is also common in patients with ILD. ${ }^{32}$ In patients with IPF, PH has a reported incidence of $32-84 \%$ and is associated with decreased exercise capacity and worse prognosis. ${ }^{33}$ Patients with $\mathrm{IPF}$, emphysema and $\mathrm{PH}$ have a particularly dismal prognosis. ${ }^{15}$ Patients with IPF may also have an increased risk of acute coronary syndrome and deep vein thrombosis. ${ }^{34}$

The clinical course and prognosis of the different types of ILD are highly variable. ${ }^{1}$ Even if pharmacological treatment is not appropriate, it is important that a patient receives the correct diagnosis so that their physician can provide appropriate information and support. Data from a US-based survey of 1,448 patients with IPF or caregivers of patients with IPF highlight that there is a need for improved patient education regarding diagnosis and management. ${ }^{3}$ Less than half of the respondents felt well informed about treatment options, and the role of pulmonary rehabilitation, supplemental oxygen and lung transplantation. ${ }^{3}$ Receiving a diagnosis with such a poor prognosis may be difficult for the patient, and they may need time to start to come to terms with the diagnosis before they can fully comprehend the information they receive. Patients may also benefit from contacting patient organisations for advice and support.

\begin{tabular}{|c|c|c|}
\hline & $I L D$ & $C O P D$ \\
\hline \multicolumn{3}{|l|}{ Physical examination } \\
\hline Inspiratory crackles ${ }^{21}$ & $\checkmark$ & $x$ \\
\hline Wheezing $^{14}$ & $x$ & $\checkmark$ \\
\hline Finger clubbing 22 & $\checkmark$ & $x$ \\
\hline \multicolumn{3}{|l|}{ Spirometry ${ }^{16}$} \\
\hline Reduction in TLC & $\checkmark$ & $x$ \\
\hline Reduced $\mathrm{FEV}_{1} / \mathrm{FVC}$ ratio & $x$ & $\checkmark$ \\
\hline $\begin{array}{l}\text { Response to } \\
\text { bronchodilators }\end{array}$ & $x$ & $\checkmark$ \\
\hline Chest radiographs $^{1}$ & $\begin{array}{c}\text { Show specific patterns of } \\
\text { abnormality }\end{array}$ & $\begin{array}{l}\text { Largely } \\
\text { normal }\end{array}$ \\
\hline
\end{tabular}

The majority of patients with ILD should have the opportunity for referral to a pulmonary rehabilitation programme. Comprehensive programmes involve not only exercise training with aerobic conditioning, strength and endurance training and respiratory therapy, but also behaviour modification techniques. ${ }^{35}$ In a large cohort of 402 patients with IPF, pulmonary rehabilitation had a positive effect on patients' pulmonary function and quality of life. ${ }^{36}$

At present, lung transplant is the only therapy that has been shown to improve survival in patients with IPF, but it is available only to selected patients. ${ }^{22}$ The eligibility criteria for lung transplantation vary between and even within countries, but international guidelines stress that the early referral of patients with IPF for transplantation should be promoted. ${ }^{37}$ Prompt diagnosis of IPF also makes it more likely that a patient will meet the criteria for participation in a clinical trial; most clinical trials in IPF are restricted to patients with mild or moderate impairment of lung function.

\section{CONCLUSIONS}

ILD presents with symptoms similar to other chronic respiratory conditions and is frequently misdiagnosed in primary care, most commonly as COPD and heart failure. Prompt diagnosis of ILD is important to ensure that patients receive appropriate care and support, and to enable them to be considered for lung transplantation or clinical trials. PCPs have a key role to play in expediting the diagnosis of ILD by referring middle-aged/elderly patients with unexplained chronic dyspnoea and cough who do not meet the diagnostic criteria for other diseases to an ILD centre or pulmonologist with expertise in this group of disorders.

\section{ACKNOWLEDGEMENTS}

The authors acknowledge the medical writing assistance provided by Clare Ryles and Wendy Morris of Fleishman-Hillard Group, 40 Long Acre, London, during the preparation of this review.

\section{CONTRIBUTIONS}

JDZ and DP drafted this article, with medical writing assistance from Clare Ryles and Wendy Morris of Fleishman-Hillard Group. The authors are fully responsible for all content and editorial decisions, were involved at all stages of manuscript development, and have approved the final version of the review, which reflects the authors' interpretation and conclusions. 


\section{COMPETING INTERESTS}

JDZ is a member of the InterMune Pharmaceuticals Clinical Advisory Board. DP has been a consultant to and/or member of the advisory boards for Almirall, AstraZeneca, Boehringer Ingelheim, Chiesi, GlaxoSmithKline, Medapharma, Merck, Mundipharma, Napp, Novartis, Nycomed, Pfizer, Sandoz and Teva. He or his research team have received grants and support for research in respiratory disease from the following organisations in the last 5 years: UK National Health Service, Aerocrine, AstraZeneca, Boehringer Ingelheim, Chiesi, GlaxoSmithKline, Merck, Mundipharma, Novartis, Nycomed, Orion, Pfizer, Takeda and Teva. He has received payment for lectures from Activaero, Almirall, AstraZeneca, Boehringer Ingelheim, Chiesi, Cipla, GlaxoSmithKline, Kyorin, Merck, Mundipharma, Napp, Novartis, Pfizer and Teva, and has been paid for development of educational materials by Boehringer Ingelheim and GlaxoSmithKline. He has been reimbursed for travel expenses by Boehringer Ingelheim, Merck, Mundipharma Napp, Novartis and Teva. He holds shares in AKL, which produces phytopharmaceuticals and owns $80 \%$ of Research in Real Life and its subsidiary social enterprise Optimum Patient Care.

\section{FUNDING}

The authors have not received payment for this article. Medical writing assistance was funded by Boehringer Ingelheim Pharmaceuticals.

\section{REFERENCES}

1 American Thoracic Society. American Thoracic Society/European Respiratory Society international multidisciplinary consensus classification of the idiopathic interstitial pneumonias. Am J Respir Crit Care Med 2002; 165: 277-304.

2 Coultas DB, Zumwalt RE, Black WC, Sobonya RE. The epidemiology of interstitial lung diseases. Am J Respir Crit Care Med 1994; 150: 967-972.

3 Collard HR, Tino G, Noble PW, Shreve MA, Michaels M, Carlson B et al. Patient experiences with pulmonary fibrosis. Respir Med 2007; 101: 1350-1354.

4 Travis WD, Costabel U, Hansell DM, King TE Jr, Lynch DA, Nicholson AG et al. An official American Thoracic Society/European Respiratory Society statement update of the international multidisciplinary classification of the idiopathic interstitial pneumonias. Am J Respir Crit Care Med 2013; 188: 733-748.

5 Schwaiblmair M, Behr W, Haeckel T, Markl B, Foerg W, Berghaus T. Drug induced interstitial lung disease. Open Respir Med J 2012; 6: 63-74.

6 de Boer S, Wilsher M. Review series: aspects of interstitial lung disease. Sarcoidosis. Chron Respir Dis 2010; 7: 247-258.

7 Olson AL, Swigris JJ, Sprunger DB, Fischer A, Fernandez-Perez ER, Solomon J et al. Rheumatoid arthritis-interstitial lung disease-associated mortality. Am J Respir Crit Care Med 2011; 183: 372-378.

8 Ryerson CJ, Urbania TH, Richeldi L, Mooney JJ, Lee JS, Jones KD et al. Prevalence and prognosis of unclassifiable interstitial lung disease. Eur Respir $J$ 2013; 42: 750-757.

9 Kim DS, Collard HR, King TE Jr. Classification and natural history of the idiopathic interstitial pneumonias. Proc Am Thorac Soc 2006; 3: 285-292.

10 Vancheri C, Failla M, Crimi N, Raghu G. Idiopathic pulmonary fibrosis: a disease with similarities and links to cancer biology. Eur Respir J 2010; 35: 496-504.

11 Lawson WE, Loyd JE. The genetic approach in pulmonary fibrosis: can it provide clues to this complex disease? Proc Am Thorac Soc 2006; 3: 345-349.

12 Raghu G, Collard HR, Egan JJ, Martinez FJ, Behr J, Brown KK et al. An official ATS/ERS/JRS/ALAT statement: idiopathic pulmonary fibrosis: evidence-based guidelines for diagnosis and management. Am J Respir Crit Care Med 2011; 183: 788-824.

13 Nalysnyk L, Cid-Ruzafa J, Rotella P, Esser D. Incidence and prevalence of idiopathic pulmonary fibrosis: review of the literature. Eur Respir Rev 2012; 21: 355-361.

14 Global Strategy for the Diagnosis, Management and Prevention of COPD. Global Initiative for Chronic Obstructive Lung Disease (GOLD) 2014. (2014). http://www goldcopd.org (accessed 11 May 2014).

15 Cottin V, Le PJ, Prevot G, Mal H, Humbert M, Simonneau G et al. Pulmonary hypertension in patients with combined pulmonary fibrosis and emphysema syndrome. Eur Respir J 2010; 35: 105-111.

16 Pellegrino R, Viegi G, Brusasco V, Crapo RO, Burgos F, Casaburi R et al. Interpretative strategies for lung function tests. Eur Respir J 2005; 26: 948-968.
17 Ley B, Collard HR, King TE Jr. Clinical course and prediction of survival in idiopathic pulmonary fibrosis. Am J Respir Crit Care Med 2011; 183: 431-440.

18 National Institute for Health and Care Excellence (NICE). Clinical Knowledge Summary on breathlessness (2014). http://cks.nice.org.uk/breathlessness\#! scenariorecommendation:7 (accessed 11 May 2014).

19 Lynch DA, Travis WD, Muller NL, Galvin JR, Hansell DM, Grenier PA et al. Idiopathic interstitial pneumonias: CT features. Radiology 2005; 236: 10-21.

20 Baumgartner KB, Samet JM, Coultas DB, Stidley CA, Hunt WC, Colby TV et al. Occupational and environmental risk factors for idiopathic pulmonary fibrosis: a multicenter case-control study. Collaborating Centers. Am J Epidemiol 2000; 152 307-315.

21 Cottin V, Cordier JF. Velcro crackles: the key for early diagnosis of idiopathic pulmonary fibrosis? Eur Respir J 2012; 40: 519-521.

22 Borchers AT, Chang C, Keen CL, Gershwin ME. Idiopathic pulmonary fibrosis-an epidemiological and pathological review. Clin Rev Allergy Immunol 2011; 40: 117-134.

23 Bradley B, Branley HM, Egan JJ, Greaves MS, Hansell DM, Harrison NK et al. Interstitial lung disease guideline: the British Thoracic Society in collaboration with the Thoracic Society of Australia and New Zealand and the Irish Thoracic Society. Thorax 2008; 63: v1-58.

24 King TE Jr, Bradford WZ, Castro-Bernardini S, Fagan EA, Glaspole I, Glassberg MK et al. A phase 3 trial of pirfenidone in patients with idiopathic pulmonary fibrosis. N Engl J Med 2014; 370: 2083-2092.

25 Richeldi L, du Bois RM, Raghu G, Azuma A, Brown KK, Costabel U et al. Efficacy and safety of nintedanib in idiopathic pulmonary fibrosis. N Engl J Med 2014; 370: 2071-2082.

26 Raghu G, Anstrom KJ, King TE Jr, Lasky JA, Martinez FJ. Prednisone, azathioprine, and N-acetylcysteine for pulmonary fibrosis. N Engl J Med 2012; 366: 1968-1977.

27 Noth I, Anstrom KJ, Calvert SB, de Andrade J, Flaherty KR, Glazer C et al. A placebocontrolled randomized trial of warfarin in idiopathic pulmonary fibrosis. Am $\mathrm{J}$ Respir Crit Care Med 2012; 186: 88-95.

28 Idiopathic Pulmonary Fibrosis Clinical Research Network, Martinez FJ, de Andrade JA, Anstrom KJ, King TE Jr, Raghu G. Randomized trial of acetylcysteine in idiopathic pulmonary fibrosis. N Engl J Med 2014; 370: 2093-2101.

29 Soares RV, Forsythe A, Hogarth K, Sweiss NJ, Noth I, Patti MG. Interstitial lung disease and gastroesophageal reflux disease: key role of esophageal function tests in the diagnosis and treatment. Arq Gastroenterol 2011; 48: 91-97.

30 Raghu G, Freudenberger TD, Yang S, Curtis JR, Spada C, Hayes J et al. High prevalence of abnormal acid gastro-oesophageal reflux in idiopathic pulmonary fibrosis. Eur Respir J 2006; 27: 136-142.

31 Lee JS, Ryu JH, Elicker BM, Lydell CP, Jones KD, Wolters PJ et al. Gastroesophageal reflux therapy is associated with longer survival in patients with idiopathic pulmonary fibrosis. Am J Respir Crit Care Med 2011; 184: 1390-1394.

32 Hallowell RW, Reed RM, Fraig M, Horton MR, Girgis RE. Severe pulmonary hypertension in idiopathic nonspecific interstitial pneumonia. Pulm Circ 2012; 2: 101-106.

33 Pitsiou G, Papakosta D, Bouros D. Pulmonary hypertension in idiopathic pulmonary fibrosis: a review. Respiration 2011; 82: 294-304.

34 Hubbard RB, Smith C, Le Jl, Gribbin J, Fogarty AW. The association between idiopathic pulmonary fibrosis and vascular disease: a population-based study. Am J Respir Crit Care Med 2008; 178: 1257-1261.

35 Holland A, Hill C. Physical training for interstitial lung disease. Cochrane Database Syst Rev 2008; (4): CD006322.

36 Huppmann P, Sczepanski B, Boensch M, Winterkamp S, Schönheit-Kenn U, Neurohr $C$ et al. Effects of inpatient pulmonary rehabilitation in patients with interstitial lung disease. Eur Respir J 2013; 42: 444-453.

37 Orens JB, Estenne M, Arcasoy S, Conte JV, Corris P, Egan JJ et al. International guidelines for the selection of lung transplant candidates: 2006 update-a consensus report from the Pulmonary Scientific Council of the International Society for Heart and Lung Transplantation. J Heart Lung Transplant 2006; 25: 745-755.

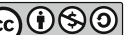

This work is licensed under a Creative Commons AttributionNonCommercial-ShareAlike 4.0 International License. The images or other third party material in this article are included in the article's Creative Commons license, unless indicated otherwise in the credit line; if the material is not included under the Creative Commons license, users will need to obtain permission from the license holder to reproduce the material. To view a copy of this license, visit http:// creativecommons.org/licenses/by-nc-sa/4.0/ 